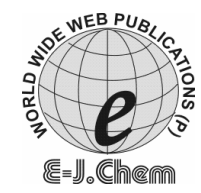

http://www.e-journals.net

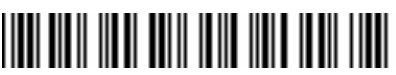

ISSN: 0973-4945; CODEN ECJHAO

E-Journal of Chemistry

Vol. 5, No.3, pp. 473-478, July 2008

\title{
Simple Spectrophotometric Determination of Torsemide in Bulk Drug and in Formulations
}

\author{
MAROTHU VAMSI KRISHNA* and DANNANA GOWRI SANKAR \\ Pharmaceutical Analysis and Quality Assurance Division, \\ College of Pharmaceutical Sciences, \\ Andhra University, Visakhapatnam, India. \\ marothu_vamsi@rediffmail.com
}

Received 7 April 2007; Accepted 12 June 2007

\begin{abstract}
A simple and cost effective spectrophotometric method is described for the determination of torsemide in pure form and in pharmaceutical formulations. The method is based on the formation of blue colored chromogen when the drug reacts with Folin-Ciocalteu (F-C) reagent in alkaline medium. The colored species has an absorption maximum at $760 \mathrm{~nm}$ and obeys beer's law in the concentration range $30-150 \mu \mathrm{g} \mathrm{mL}^{-1}$. The absorbance was found to increase linearly with increasing concentration of TSM, which is corroborated by the calculated correlation coefficient value of $0.9999(n=8)$. The apparent molar absorptivity and sandell sensitivity were $1.896 \times 10^{3} \mathrm{~L} \mathrm{~mol}^{-1}$ $\mathrm{cm}^{-1}$ and $0.183 \mu \mathrm{g} \mathrm{cm}^{-2}$, respectively. The slope and intercept of the equation of the regression line are $5.4 \times 10^{-3}$ and $1.00 \times 10^{-4}$ respectively. The limit of detection was 0.94 . The optimum experimental parameters for the reaction have been studied. The validity of the described procedure was assessed. Statistical analysis of the results has been carried out revealing high accuracy and good precision. The proposed method was successfully applied to the determination of TSM in pharmaceutical formulations.
\end{abstract}

Keywords: Torsemide, spectrophotometry, F-C, Reagent, Determination.

\section{Introduction}

Torsemide (TSM) $)^{1-2}$ is loop diuretic and is chemically known as 3-pyridine sulfonamide $\mathrm{N}$ [[(1-methylethyl) amino] - carbonyl]-4-[(3-methylphenyl) amino], whose structure is given in Figure 1. It acts by inhibiting the $\mathrm{Na}^{+} / \mathrm{K}^{+} / 2 \mathrm{Cl}^{-}$carrier system(via interference of the chloride binding site) in the lumen of the thick ascending portion of the loop of Henle, resulting in the decrease in reabsorption of sodium and chloride. Literature survey reveals that, few chromatographic methods ${ }^{3-6}$ have been reported for the estimation of TSM in human plasma and urine. To the best of our knowledge, there is no work in the literature reported about the visible spectrophotometric method for the analysis of TSM in either 
biological fluids or pharmaceutical formulations. Hence the author has made an attempt to develop simple and sensitive spectrophotometric method for the estimation of TSM in pure drug and in pharmaceutical formulations. The purpose of this investigation was to develop a simple and sensitive visible spectrophotometric method for the quantization of TSM in pure drug and in pharmaceutical formulations. The method uses the well known reduction reaction involving Folin-Ciocalteu (F-C) reagent and TSM resulting in the formation of a blue chromogen that could be measured at $760 \mathrm{~nm}$.

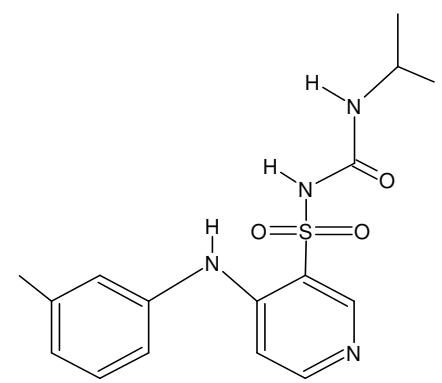

Figure 1. Structure of torsemide

\section{Experimental}

\section{Apparatus}

All spectral and absorbance measurements were made on a Systronic model 106 digital spectrophotometer with $10 \mathrm{~mm}$ matched quartz cells.

\section{Materials and reagents}

All chemicals used were of analytical reagent grade and double distilled water was used throughout. TSM was obtained from Dr.Reddy's labs Hyderabad. Dytor and torsinex are the commercial tablet formulations labeled to contain 10 and $20 \mathrm{mg}$ of TSM per tablet respectively.F.C. reagent $(2 \mathrm{~N})$ supplied by S.d. Fine chem. India, Ltd., was used by diluting $50 \mathrm{~mL}$ to $100 \mathrm{~mL}$ with distilled water. Sodium hydroxide solution (4\%) was prepared by dissolving $4 \mathrm{~g}$ of sodium hydroxide in $100 \mathrm{~mL}$ of distilled water.

$300 \mu \mathrm{g} / \mathrm{mL}$ Stock reference solution was freshly prepared from pure sample of TSM by dissolving $0.03 \mathrm{~g}$ in $100 \mathrm{~mL}$ of distilled water.

\section{General procedure}

In to $10 \mathrm{~mL}$ measuring flasks, different aliquots of working standard solution $(1.0-5.0 \mathrm{~mL})$ were transferred to provide final concentration range $30.0-150.0 \mu \mathrm{g} \mathrm{mL}^{-1}$. To each flask, $1.5 \mathrm{~mL}$ of sodium hydroxide and $1.5 \mathrm{~mL}$ of $\mathrm{F}-\mathrm{C}$ were successively added and kept a side for $5 \mathrm{~min}$. The solutions were made up to volume with distilled water. The absorbance of each solution was measured at $760 \mathrm{~nm}$ against the reagent blank. The calibration graph was then prepared by plotting the absorbance versus concentration of the drug. The concentration of the unknown was read from the calibration graph or computed from the regression equation.

\section{Procedure for tablets}

Twenty tablets were weighed accurately and ground in to a fine powder. An amount of powder equivalent to $30 \mathrm{mg}$ of TSM was weighed into a $100 \mathrm{~mL}$ volumetric flask, $50 \mathrm{~mL}$ of the distilled water was added and shaken thoroughly for about $10 \mathrm{~min}$, then the volume was made up to the mark with the distilled water, mixed well and filtered using a quantitative filter paper. The assay of the tablets was completed according to the general procedure. 


\section{Results and Discussion}

The F-C reagent is used in the determination of many phenolic compounds ${ }^{7}$ and a large number of substances of pharmaceutical interest ${ }^{8-15}$. The proposed method is based on the formation of a blue colored chromogen, following the reduction of phosphor-molybdo tungstic mixed acid of the F-C reagent ${ }^{16}$ by TSM, in the presence of sodium hydroxide, which could be measured at $760 \mathrm{~nm}$. The mixed acids in the F-C reagent are the final chromogen and involve the following chemical species:

$$
\begin{gathered}
3 \mathrm{H}_{2} \mathrm{O} . \mathrm{P}_{2} \mathrm{O}_{5} .13 \mathrm{WO}_{3} .5 \mathrm{MoO}_{3} .10 \mathrm{H}_{2} \mathrm{O} \\
\text { and } \\
3 \mathrm{H}_{2} \mathrm{O}_{2} \mathrm{P}_{2} \mathrm{O}_{5} .14 \mathrm{WO}_{3} .4 \mathrm{MoO}_{3} .10 \mathrm{H}_{2} \mathrm{O}
\end{gathered}
$$

TSM probably effects reduction of 1,2 or 3 oxygen atoms from tungstate and / or molybdate in the F-C reagent, there by producing one more possible reduced species which have characteristic intense blue color.

The effect of different variables such as nature and strength of alkali, optimum volumes of $\mathrm{NaOH}$ and F-C reagent, reaction time and order of addition of reactants were studied and optimized for attainment of maximum color and stability of colored species.

\section{Optimization of conditions, and absorption spectrum of the reaction product}

Condition under which reaction of TSM with F-C reagent fulfils the essential requirements was investigated. All conditions studied were optimized at room temperature $\left(32 \pm 2^{0} \mathrm{C}\right)$.

\section{Selection of reaction medium}

To find a suitable medium for the reaction, different aqueous bases were used, such as borax, sodium hydroxide, sodium carbonate or bicarbonate, sodium acetate and sodium hydrogen phosphate. The best results were obtained when sodium hydroxide was used. In order to determine the optimum concentration of sodium hydroxide, different volumes of $4 \%$ sodium hydroxide solution $(0.5,1.0 .2 .0,2.3 .3 .0 \mathrm{~mL})$ were used to a constant concentration of TSM $\left(90 \mu \mathrm{g} \mathrm{mL}^{-1}\right)$ and the results of the observation are plotted in Figure 2. From the figure it is evident that $1.5 \mathrm{~mL}$ of $4 \%$ sodium hydroxide solution was found optimum. Larger volumes had no effect on the absorbance of the colored species.

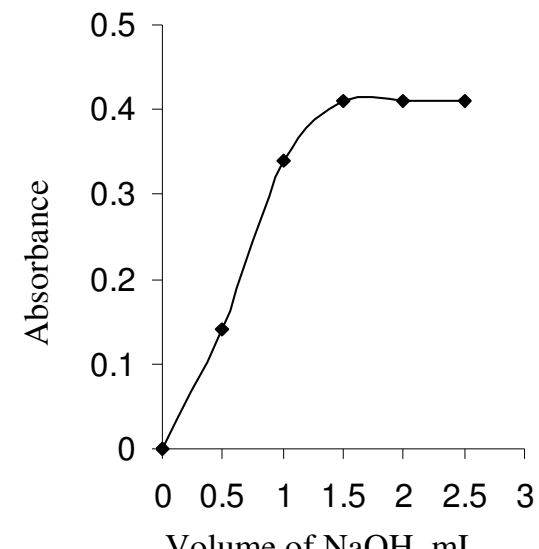

Volume of $\mathrm{NaOH}, \mathrm{mL}$

Figure2. Effect of sodium hydroxide concentration $\left(90 \mu \mathrm{g} \mathrm{mL} \mathrm{m}^{-1}\right.$ drug $+1.0 \mathrm{~mL}$ of F-C reagent) 


\section{Effect of $F$-C reagent concentration}

Several experiments were carried out to study the influence of F-C reagent concentration on the color development and the results are shown in Figure 3. It is apparent that $1.5 \mathrm{~mL}$ of reagent gave maximum color and $1.5 \mathrm{~mL}$ of reagent in a total volume of $10 \mathrm{~mL}$ was used through out the work.

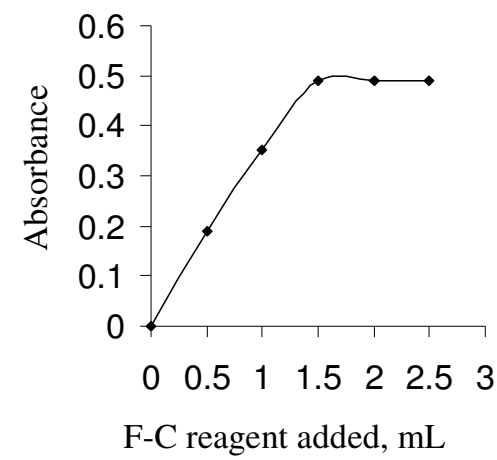

Figure 3. Effect of F-C reagent concentration $\left(90 \mu \mathrm{g} \mathrm{mL} \mathrm{m}^{-1}\right.$ drug $+1.5 \mathrm{~mL}$ of sodium hydroxide

\section{Reaction time and stability of the colored species}

The color reaction is not instantaneous. Maximum color is developed with in $5 \mathrm{~min}$ of mixing the reactants and is stable for 30min thereafter.

\section{Effect of order of addition of reactants}

After fixing all other experimental variables, a few further experiments were performed to ascertain the influence of order of addition of reactants on the color development and the results are presented in Table 1. The order of addition of serial numbers 1, 2, 3 or 6 recommended.

Table 1. Effect of order of addition of reactants on color development

\begin{tabular}{ccc}
\hline S.No. & \multicolumn{1}{c}{ Order of addition } & Absorbance $^{\mathrm{a}}$ \\
\hline 1 & TSM +F-C reagent + NaOH & 0.16 \\
2 & TSM+ NaOH+ F-C reagent & 0.16 \\
3 & F-C reagent+ TSM+ + NaOH & 0.16 \\
4 & F-C reagent + NaOH + TSM & 0.01 \\
5 & $\mathrm{NaOH}+\mathrm{F}-\mathrm{C}$ reagent + TSM & 0.01 \\
6 & $\mathrm{NaOH}+\mathrm{TSM}+\mathrm{F}-\mathrm{C}$ reagent & 0.16 \\
${ }^{a}$ For 30 $\mu g \mathrm{~mL}^{-1}$ of TSM.
\end{tabular}

\section{Absorption spectrum and calibration graph}

Absorption spectrum of the colored complex was scanned in the double beam mode against a reagent blank in the range $400-800 \mathrm{~nm}$. The reaction product show absorption maximum at $760 \mathrm{~nm}$.

Calibration graph was obtained according to the above general procedure. The linearity (eight replicates for five different concentrations) was checked by a linear least -squares treatment. All the spectral characteristics and the measured or calculated factors and parameters are summarized in Table 2 . 
Table 2. Optical and Regression Characteristics, Precision and Accuracy of the Proposed Method for TSM

\begin{tabular}{|c|c|}
\hline Parameter & Values \\
\hline$\lambda_{\max }, \mathrm{nm}$ & 760 \\
\hline Beer's law limits, $\mu \mathrm{g} \mathrm{mL}^{-1}$ & $30.0-150.0$ \\
\hline Detection limit, $\mu \mathrm{g} \mathrm{mL}^{-1}$ & 0.9414 \\
\hline Molar absorptivity, $\mathrm{L}_{\text {mole }}{ }^{-1} \mathrm{~cm}^{-1}$ & $1.896 \times 10^{3}$ \\
\hline Sandell's sensitivity, $\mu \mathrm{g} \mathrm{cm}^{-2} / 0.001$ absorbance unit & 0.183 \\
\hline Optimum photometric range, $\mu \mathrm{g} \mathrm{mL}^{-1}$ & $32.0-148.0$ \\
\hline \multicolumn{2}{|l|}{ Regression equation $(\mathrm{Y}=\mathrm{a}+\mathrm{bC})$} \\
\hline Slope (b) & $5.4 \times 10^{-3}$ \\
\hline Standard deviation of slope $\left(\mathrm{S}_{\mathrm{b}}\right)$ & $0.20 \times 10^{-4}$ \\
\hline Intercept (a) & $1.00 \times 10^{-4}$ \\
\hline Standard deviation of intercept $\left(S_{a}\right)$ & $0.17 \times 10^{-2}$ \\
\hline Standard error of estimation $\left(S_{e}\right)$ & $0.16 \times 10^{-2}$ \\
\hline Correlation coefficient $(r)$ & 0.9999 \\
\hline Relative standard deviation $\%^{\text {a }}$ & 0.223 \\
\hline \multicolumn{2}{|l|}{$\%$ Range of error(Confidence limits) ${ }^{\mathrm{a}}$} \\
\hline 0.05 level & 0.187 \\
\hline 0.01 level & 0.277 \\
\hline$\%$ Error in bulk samples ${ }^{\mathrm{b}}$ & 0.172 \\
\hline
\end{tabular}

${ }^{a}$ Average of eight determinations; ${ }^{b}$ Average of three determinations In $Y=a+b C, Y$ is absorbance and $C$ is concentration.

Sensitivity, accuracy and precision

Sandell's sensitivity, molar absorptivity, precision and accuracy were found by performing eight replicate determinations containing $3 / 4^{\text {th }}$ of the amount of the upper beer's law limits. The measured standard deviation (S.D.), Relative standard deviation (RSD), and confidence limits (Table 2) can be considered satisfactory.

\section{Interference}

Reducing ions, trytophan, hydroxyproline, 2- and 3-hydroxypridines, ascorbic acid and uric acid also reduce F-C reagent to molybdenum blue. However these substances are seldom present in the reagents and used and in the pharmaceutical formulations. Hence, the method is devoid of error due to above substances.

Table 3. Results of analysis of tablet formulations containing TSM

\begin{tabular}{|c|c|c|c|c|c|}
\hline \multirow{2}{*}{ Formulation } & \multirow{2}{*}{$\begin{array}{c}\text { Labeled } \\
\text { amount,mg }\end{array}$} & \multicolumn{2}{|c|}{ Recovery $^{\mathrm{a}} \pm$ S.D, $\%$} & \multirow{2}{*}{$t^{b}$} & \multirow{2}{*}{$\mathrm{F}^{\mathrm{c}}$} \\
\hline & & proposed & Reference & & \\
\hline Dytor & 10 & $99.95 \pm 0.091$ & $98.00 \pm 0.102$ & 0.99 & 1.21 \\
\hline Torsinex & 20 & $100.13 \pm 0.065$ & $100.05 \pm 0.098$ & 1.56 & 2.25 \\
\hline
\end{tabular}

${ }^{a}$ Average of six determinations; ${ }^{b}$ Calculated $t$-value; tabulated $t$-value for five degrees of freedom; and $p=0.05$ is 2.57; ${ }^{c}$ Calculated $F$-value; tabulated $F$-value for five degrees of freedom; and $95 \%$; confidence limits is 5.05 . 


\section{Application to formulations}

The proposed procedure was applied to the determination of TSM in commercially available tablets. The same samples were analyzed, simultaneously by the UV reference method and the proposed method. The results obtained from the two sets of analyses were compared statistically. The student's t-values and F-values at the 95\% confidence level did not exceed the tabulated values of 2.57 and 5.05 respectively(for five degrees of freedom) indicates no significant difference between the methods in so far as accuracy and precision are concerned. Table 3 summarizes these results.

\section{Conclusions}

The proposed method is thus simple, rapid, precise and inexpensive, and hence can be used in routine analysis of TSM in bulk drug and in formulations.

\section{References}

1. Blose J L, Adams K F and Patterson J H, Ann Pharmaco Ther., 1995, 29, 396-402.

2. Flower S F and Murray K M, Am J Health Syst.Pharm., 1995, 52, 1771-1780.

3. March, Clark, Farthing, Don, Brain W, Felder B, Eberhard, Karnes and Thomas H, J. Pharm.Sci., 1990, 79, 453-457.

4. Karnes, Thomas H, Farthing, Don, Felder B and Eberhard., J. Liq. Chromatogr. 1989, 12, 1809-18018.

5. Qin Y, Yang X B, Wang C, Zhow M, Wn M T, Xu Y X, Peng S Q and Shiqi. Fenxi Ceshi Xuebao., 2003, 22, 41-44.

6. Qin Y, Yang X B, Wang C, Zhow M, Wn M T, Xu Y X and Peng S Q. J. Chromatogr., B: Anal. Technol. Biomed. Life Sci., 2003, 79, 193-203.

7. Pesez $\mathrm{M}$ and Bartos J, Colorimetric and fluorimetric analysis of organic Compounds and drugs; Marcel Dekker: New York, 1974, pp 83.

8. Avadhanulu A B and Pantulu A R R, East. Pharm., 1993, 36, 125-126.

9. Devala Rao G, Girish kumar K and Chowdary K P R, J. Indian Council. Chemists., 2000, 17, 32-34.

10. Lakshmi C S R and Reddy M N, J. Inst. Chem. (India). 1998, 70, 152-155.

11. Meyyanthan S N, Ravisankar S and Suresh B, East. Pharm., 1994, 37, 49-50.

12. Meyyanthan S N, Ravisankar S and Suresh B, East. Pharm., 1995, 37, 125-126.

13. Narayan Reddy M, Sarisa Reddy K, Gowri Sankar D and Sreedhar K, Indian J. Pharm. Sci.. 1998, 60, 172-173.

14. Raw G R, Kanjilal G and Mohan K R, Analyst., 1978, 103, 993-994.

15. Sastry C S P, Sehma V A N and Prasad U V, J. Inst. Chem. India. 1996, 68, 140.

16. Folin O and Ciocalteu D, J. Biol. Chem. 1927, 73, 627. 


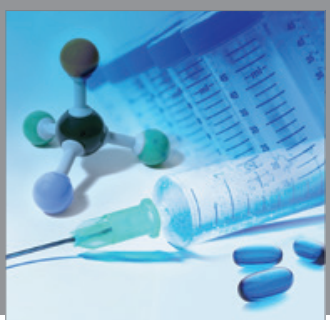

International Journal of

Medicinal Chemistry

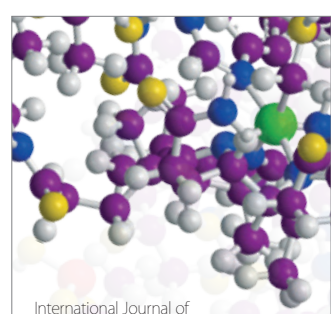

Carbohydrate Chemistry

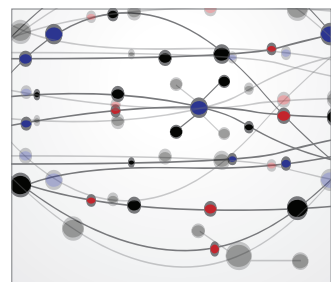

The Scientific World Journal
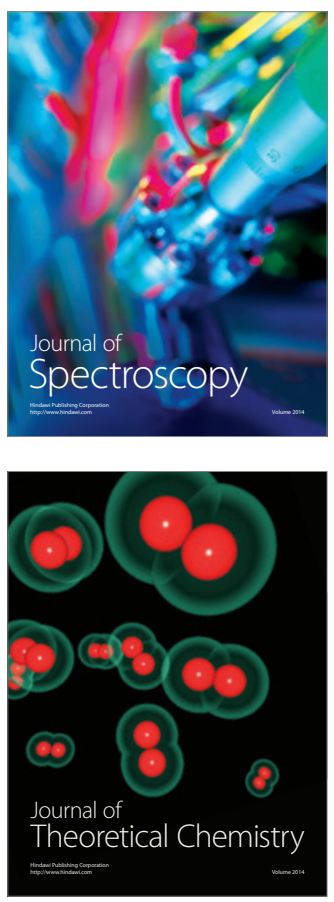
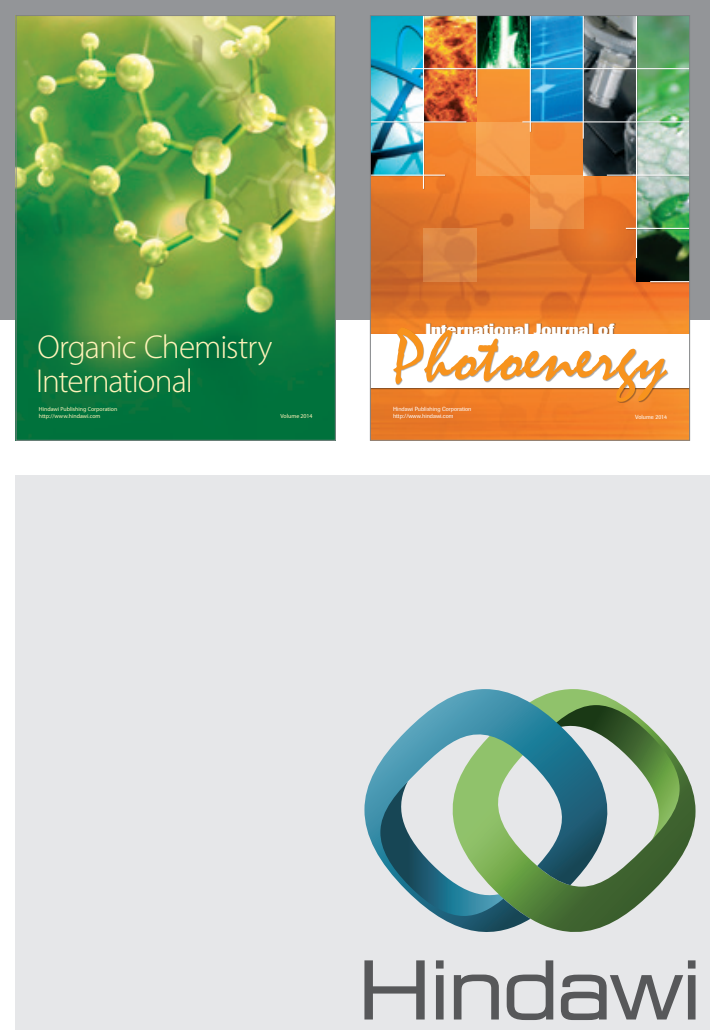

Submit your manuscripts at

http://www.hindawi.com
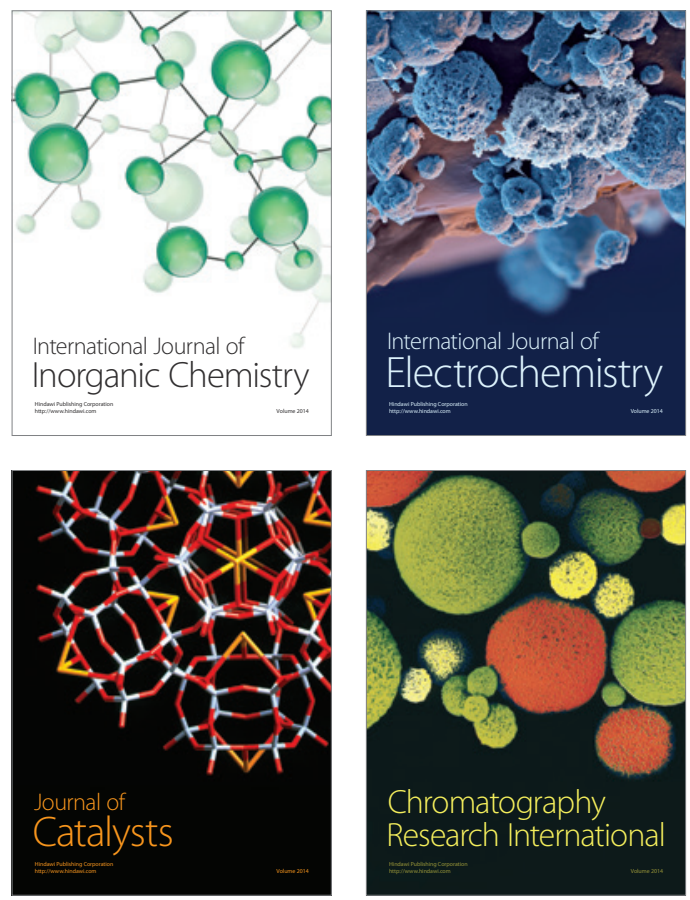
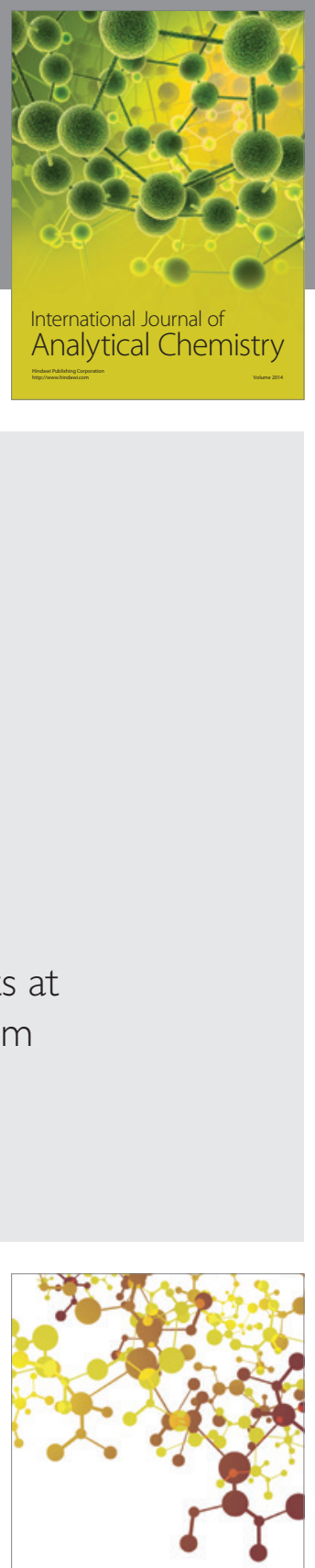

Journal of

Applied Chemistry
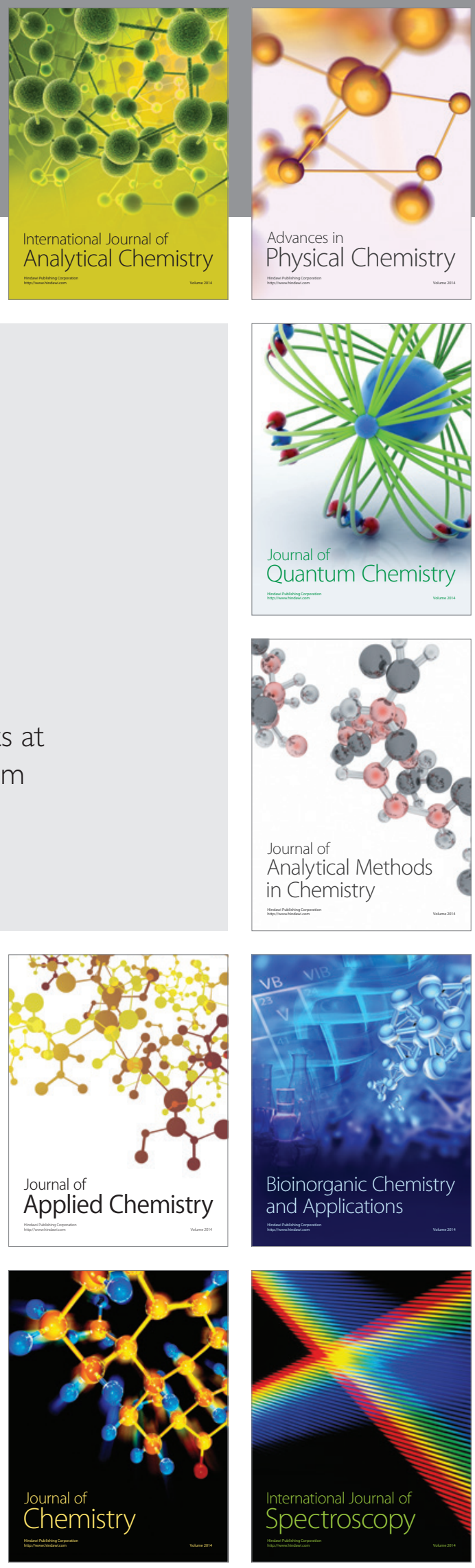